\title{
Team-based learning: An ethnicity-focused study on the perceptions of teamwork abilities of engineering students
}

\author{
D. Beneroso* and M. Erans
}

Department of Chemical and Environmental Engineering, University of Nottingham, Nottingham, United Kingdom

* daniel.benerosovallejo@nottingham.ac.uk

Dr Daniel Beneroso is an Assistant Professor in the Department of Chemical and Environmental Engineering at The University of Nottingham (UK). He is a Senior Fellow of the Higher Education Academy (SFHEA) and has completed a Postgraduate Certificate in Higher Education, awarded by the University of Nottingham in June 2019. Currently, he is one of the heads of education and student experience at the department. Daniel is interested in promoting a system engineering perspective of engineering education with a clear mission to catalyse the development of key-drivers to support institutions to become future successful leaders in engineering education. Areas such as global engineering education, curriculum development or multidisciplinary learning through innovative and humanised learning experiences are of his personal interest.

Dr Maria Erans is a postdoctoral researcher at the University of Nottingham with a special interest in energy generation/utilisation, material science and mechanical design. She has worked across several international institutions in Stuttgart (Germany), Naples (Italy) and Cranfield (UK). She is an Associate Fellow of the Higher Education Academy (AFHEA) and has been supporting the implementation of active collaborative learning pedagogies at the University of Nottingham. 


\title{
Team-based learning: An ethnicity-focused study on the perceptions of teamwork abilities of engineering students
}

\author{
A study into the influence of the team-based learning (TBL) model upon the \\ perception of White, Asian and Black and Minority Ethnic (BME) students about \\ their peers' teamwork abilities is addressed herein. A large cohort of final-year \\ engineering students grouped into 24 diverse teams assessed their team's peers \\ after completing a 10-credit TBL module by means of a peer-assessment \\ instrument that spanned the areas of individual performance, adjustment and \\ support, and decision-making. No significant differences were found in perceived \\ student adjustment and support across ethnicities. Nevertheless, despite TBL \\ having been reported to promote innovative outcomes stemming from the social \\ diversity characterising the teams, our findings suggest that the implementation \\ of TBL per se may not be enough to enhance the significantly poorer perceived \\ performance and decision-making skills of BME students when they work in \\ teams.
}

Keywords: active learning, team-based learning, TBL, BAME, inclusive pedagogies

\section{Introduction}

Higher education institutions across the world continue to invest significant resources in accelerating the transformation of their educational and student experience models in response to the $21^{\text {st }}$ century demands from industries, governments and businesses (Dori, Belcher et al. 2003, Beichner, Saul et al. 2007, Shinde and Kolmos 2011, Mitchell, Nyamapfene et al. 2019). Active learning has been widely envisaged in the education literature as an approach to foster such educational transformation, where students are placed at the core of a dynamic learning process by undertaking meaningful learning activities during which metacognitive skills are nurtured (Prince 2004, Shekhar and 
Borrego 2018, Hartikainen, Rintala et al. 2019, Hernández-de-Menéndez, Vallejo Guevara et al. 2019). In the particular case of engineering education, active learning has been empirically validated as the preferred teaching practice over conventional lecturing approaches to enhance the cognitive acquisition of learning outcomes (Freeman, Eddy et al. 2014), and has been evidenced to offer disproportionate benefits for students from underrepresented minorities (Theobald, Hill et al. 2020).

Several active learning models have been extensively used across engineering disciplines such as problem-based learning (Hsieh and Knight 2008), project-based learning (Lehmann, Christensen et al. 2008, de Los Rios, Cazorla et al. 2010), practicebased learning (Mann, Chang et al. 2020), problem-orientated and project-based learning (Lehmann, Christensen et al. 2008), or team-based learning (TBL) (Najdanovic-Visak 2017); TBL having risen its popularity in the last few years. TBL is a teaching model firmly grounded in the social constructivist educational theory (Vygotsky 1980, Hrynchak and Batty 2012) and is based on collaborative learning that follows a systematic sequence of individual work, group work and immediate feedback to create a motivational framework in which students progressively hold each other accountable for coming to class prepared and willing to contribute to discussion (Michaelsen, Sweet et al. 2008). TBL has also been reported to provide students with early practice at professional and teamwork competencies (Betta 2016).

The TBL sequence includes three phases for each of the module units (Figure 1). The first phase involves individual students studying a pre-reading document or an instructional video designed to introduce the underpinning theoretical concepts that students need to be familiar with to effectively participate in the next two phases of the sequence. The second phase consists of a readiness assurance process (RAP) by means of which students complete an individual multichoice test (iRAT) that supports them in 
identifying whether they have achieved the learning outcomes covered in the first phase, followed by a team test (tRAT) where all the peer team members work together to complete the same test. The questions are focused on assessing the students at the lowest levels of cognitive skills; i.e. gaining knowledge and comprehending. Immediate feedback is given to teams by means of scratch cards that reveal the right answers to the tRAT questions. Overall, the RAT systematically increases students' intrinsic motivation, identified regulation, perceived competence, and perceived autonomy support (Jeno, Raaheim et al. 2017). Following the immediate feedback, educators provide a brief explanation of questions that may have been wrongly answered by a great majority of teams. Finally, the third phase consists of a collection of team application exercises (tAPP) where peers work together by applying, analysing, synthesising and/or evaluating higher cognitive level concepts grounding on the acquired knowledge during the RAT phase (Whitley, Bell et al. 2015). tAPP exercises typically follow the $4 \mathrm{~S}$ framework: Significant problems, Same problem, Specific choice and Simultaneous report. Teams are provided with different solutions and they have to report their choice at the same time after which a discussion is held between teacher and students to address knowledge shortcomings (Michaelsen, Sweet et al. 2008).

\section{Insert Figure 1 here}

TBL has been regarded as an inclusive teaching model in the sense that educators are responsible for creating diverse, long-term teams of five to seven students characterised by mixed genders, ethnicities, home countries and academic abilities; these differences often reported to be the driver to the team success (Greetham and Ippolito 
2018). Furthermore, Michaelsen et al. claimed that TBL closes the attainment gap commonly observed between White and Black, Asian and Minority Ethnic (BAME) students (Michaelsen, Sweet et al. 2008), although this statement has been challenged (Cartwright 2017). Different mechanisms have been proposed to explain such a gap reduction; for instance, the fact of designing a course in a highly-structured way (such as TBL) has demonstrated to largely benefit students from minority backgrounds (Haak, HilleRisLambers et al. 2011). More recently, researchers postulated that active learning methodologies, such as TBL, positively affect student well-being, therefore enhancing their cognitive learning (Ballen, Wieman et al. 2017). Regardless of the differences in learning outcomes exhibited by TBL students, this educational model still allows for a more inclusive learning environment when compared to more conventional teaching methodologies (Lane 2008, Chao and Pardy 2014, Greetham and Ippolito 2018).

A fewer number of rigorous studies have been conducted to assess the development of teamwork skills in TBL modules. O'Neill and Salas recently examined what constitutes a high-performing team (O'Neill and Salas 2018) and provided a set of guidelines for designing courses for effective teamwork engagement (O’Neill, Larson et al. 2019). Not only high performing teams deliver on stakeholder goals at high quality level, but they also evolve over time into progressively capable working units, allowing their members to grow and develop. These researchers presented a set of strategies for helping teams to develop a high-performance way of working under four different themes: work across boundaries, build effective team processes and states, manage team development issues, and leverage human capital (i.e., the combination of knowledge, skills, and abilities of people in the context of teams (Ployhart, Nyberg et al. 2014)). These overarching four themes are inherent to the evolution of the TBL in a classroom setting, but ultimately it is up to the educator's call the extent to which these are 
addressed. The last theme -leverage human capital- has been indeed the focus of the most recent TBL and teamwork skills development related literature, whereby a strategic application of human capital in teams can create a unique set of abilities supporting a successful team performance. Gallego and Peeters developed a methodology to measure the perception of teamwork skills among PharmD students after completing a 90-hour TBL module, concluding that previous work experience had had a positive correlation whereas demographic characteristics such as the students' age had had a negative correlation with change in teamwork perception (Gallegos and Peeters 2011). Park et al. conducted a study to evaluate the effectiveness of TBL in developing nursing students' perceived teamwork, and they found that higher tRAT scores were positively correlated with team-efficacy and team-interpersonal skills (Park, Kim et al. 2015). Baughman et al. rigorously demonstrated that TBL students developed different team dynamics from those enrolled in a conventional teaching classroom as TBL allowed enough time for team formation and development, whilst students learned to work with one another in addition to learning the subject (Baughman, Hassall et al. 2019).

Lately, Haidet et al. conducted a systematic review to ascertain how TBL has evolved over the years and suggested that TBL literature is already at a significant maturation stage, where more rigorous scholarly research is needed beyond the systemlevel question 'Does TBL work?' to provide further evidence that could help to shape the evolution of the model (Haidet, Kubitz et al. 2014). New reliable instruments such as peer-assessment questionnaires to capture students' perceptions, thoughts and feelings around the model and its social context will be required beyond the usually used performance indicator; i.e., students' results in their assessments.

Herein, we report for the first time an empirical study on an engineering cohort by means of an electronic peer-assessment tool to evaluate the following research 
question: Does implementing the team-based learning (TBL) educational model consistently develop perceived team performance, individual adjustment and support, and decision-making abilities across White, Asian and Black and Minority Ethnics (BME) engineering students? Although TBL has demonstrated to be an inclusive teaching method, it is not clear whether it is able to prompt equivalent teamwork abilities across team members beyond achieving the required cognitive learning outcomes for the learning module.

\section{Methodology}

Participants

Data for this study were collected from a year-3 BEng Hons Chemical and Environmental Engineering students' cohort at the University of Nottingham (United Kingdom). All the participants were enrolled in the 10-credit 2020 module Advanced Transport Phenomena whose main learning outcomes were to (1) to understand the principles of momentum, heat and mass transfer, and be able to apply them to problems involving flowing fluids and multiple phases, (2) to be able to apply a range of appropriate tools such as dimensional analysis and mathematical modelling to problems involving flowing fluids and multiple phases, and (3) to understand the role of empirical correlation and other approximate methods in the context of momentum, heat and mass transfer. The assessment of such learning outcomes factored the students iRAT marks ( $10 \%$ of the module mark), the students tRAT marks multiplied by an individual peer-assessment weighting factor-i.e., the WebPA factor as will be described below- (10\% of the module mark), and a final exam ( $80 \%$ of the module mark). The module was structured into two major units following the TBL cycle: preparatory work, RAP (iRAT and tRAT) and 
application exercises (tAPP) for each of the major units. The students were purposefully allocated in 24 permanent teams of five, six or seven students to ensure both team formation and cohesion of members (Miller 2003, Baughman, Hassall et al. 2019) and equivalent cognitive skills across the teams (based on the individuals' year-2 course averages). Diversity was ensured by balancing gender and ethnicity across the teams, hence providing a consistent social learning context within the 24 teams. Ethnicity characteristics of the cohort are summarised by 47 White students (52.8\%), 30 Asian students (33.7\%) and 12 Black and Minority Ethnics (BME) students (13.5\%).

\section{Data Collection}

This study was designed as a quantitative experimental research to address the research question aforementioned. After completing the two TBL units, Web-PA -a digital platform developed at Loughborough and Hull Universities (UK) - was used by creating a peer-assessment questionnaire to measure the perception of team members on their peers' teamwork abilities, and constructed based on comparative ratings, rather than on modified behaviourally anchored rating scales. This constituted the 'summative peer assessment' step of the TBL model (see Figure 1). Although the use of Web-PA is not common in the engineering education literature, it has demonstrated to be a reliable instrument to measure the contribution of individual students in teamwork activities (Stevenson, Seenan et al. 2012, Palego and Pierce 2020). The use of peer-assessment has been deeply discussed by Planas-Llado et al., who found that teams that viewed their team as functioning best distributed equal scores among their teammates in peerassessment exercises (Planas-Lladó, Feliu et al. 2020). Furthermore, Brutus et al. reported that the effectiveness of students, as perceived by their team peers, increased over time when using a centralised electronic peer evaluation system, emphasising the benefit of 
such tool for the assessment of the development of important skills in higher education (Brutus and Donia 2010). Overall, peer-assessment tools have deemed to be a more reliable performance indicator than a sole self-assessment questionnaire for the purposes of this study as suggested and discussed by Fremman (Freeman 1995).

The electronic peer-assessment questionnaire contained three items related to the areas of individuals' performance, adjustment and support, and decision-making in the realm of a diverse team, which were measured on a 5-point Likert-scale (' 1 ' meaning 'very strongly disagree' and '5' meaning 'very strongly agree'):

- Question 1 (Q1): Student X effectively fulfilled their peer role during the team-tests (tRAT) and application exercises, and their performance met my expectations

- Question 2 (Q2): Student X adjusted their way of working to actively support other fellow team members during the team-tests (tRAT) and application exercises

- Question 3 (Q3): Student $X$ actively participated in team decision-making during the team-tests (tRAT) and application exercises

Individuals were allowed to answer to the above Q1, Q2 and Q3 questions for each of their peers, but were not allowed to assess themselves. The questionnaire was reviewed and approved by the corresponding ethics committee of the Faculty of Engineering at the University of Nottingham (code B18). All participants were informed of the survey by the authors of this paper and were told the purpose of the study. Students were emailed the link to the peer-assessment questionnaire, and 88 students submitted their answers (62\% response rate). Students were given a period of one month to complete 
it and received three reminders during that time. All students signed consent forms as the first question on the survey, and they were allowed to remove their data from the study at a later date if they wished to do so. All participants answered to all the three questions for all their team's peers.

\section{Data Analysis}

Data for each of the three questions were normalised in such a way that if all the team members were perceived by their peers to equally perform across a question (i.e. Q1, Q2 or Q3), a score equal to one would be awarded to all of them; students over performing obtained a normalised score larger than 1 whereas students underperforming obtained a normalised score lower than 1 . The normalisation calculation was carried out using

\section{Equation 1:}

$$
X_{i}=\frac{\bar{x}_{\text {individual }, i}}{\bar{x}_{\text {team }, i}}
$$

where $X_{i}$ is the normalised score for an individual student in question $i, \bar{x}_{\text {individual }, i}$ is the awarded average score of such individual student in question $i$ and $\bar{x}_{t e a m, i}$ is the average score of the whole team in question $i$ based on all the team's responses to the Web-PA questionnaire.

The descriptive and inferential statistical analyses were performed using IBM SPSS Statistics version 25. Normalised data were entered to compute descriptive statistics. Frequency tables were produced with the purpose of summarising a descriptive statistics of the cohort, including means and standard deviations.

Building upon the social constructivist learning framework, knowledge is socially constructed, developed by embracing the real socially diverse context of learning, and 
therefore we would theorise that potential differences in the development of teamwork skills across different ethnic backgrounds could be minimised when TBL is in action, as all the peers in a team can work based on their preference for forms of interaction, thoughts and feelings that conflict with the mainstream behaviours conventionally needed for success in a learning environment (Au 1998). Therefore, we propose the following hypotheses for this study, selected as null hypotheses:

- Hypothesis 1: TBL implementation does not develop significant perceived differences in individuals' performance between White, Asian and BME engineering students during teamwork activities.

- Hypothesis 2: TBL implementation does not develop significant perceived differences in individuals' work adjustment and support between White, Asian and BME engineering students during teamwork activities.

- Hypothesis 3: TBL implementation does not develop significant perceived differences in individuals' participation in decision-making processes between White, Asian and BME engineering students during teamwork activities.

Owing to the categorical nature of the data, non-parametric tests were used to compare the mean ranks derived from the three categories (White, Asian and BME students). In particular, the Kruskal-Wallis test was used, where the null hypothesis is represented by the equality of mean ranks across categories. The test statistic $\mathrm{H}$ was computed using Equation 2:

$$
H=\frac{12}{n(n+1)} \sum_{j=1}^{k} \frac{R_{j}^{2}}{n_{j}}-3(n+1)
$$


where $k$ is the number of categories $(k=3), n_{j}$ is the size of the $j^{\text {th }}$ category, $R_{j}$ is the rank sum for the $j^{\text {th }}$ category, and $n$ is the total sample size, i.e. $n=\sum_{j=1}^{k} n_{j}$. The statistic $\mathrm{H}$ was then compared to the critical $\mathrm{H}$ value at a $95 \%$ level of confidence and $(k$ 1) degrees of freedom (df). Null hypotheses were rejected where $p$-values were found to be less than 0.05 (i.e., 95\% level of confidence) (Leon 1998, Cramer 2003).

Cronbach's alpha for the Web-PA questionnaire in this study was estimated to be 0.973, thus indicating a good reliability of the questionnaire scales to measure the intended outcomes from the three hypothesis outlined above (Bryman 2016).

\section{Results}

Table 1 presents the descriptive statistics of the answers to the Web-PA questionnaire, including the mean, standard deviation, minimum and maximum values for each of the questions and categories. A mean equal to unity would indicate all peers within a team were perceived to have equally contributed to the specific outcomes outlined in each of the questions. The means across the Asian and White categories are around the value of 1, whereas BME students have lower means across the three questions. Nevertheless, the standard deviations for BME students are considerably higher compared to their Asian and White counterparts, and hence the spectrum of perceived performance across the three questions is wider for BME students. The lowest score (0.25) was awarded to BME students whilst maximum scores above 1.19 were achieved by all ethnicities.

\section{Insert Table 1 here}


The inferential statistical analysis based on the Kruskal-Wallis test was performed to identify whether the normalised questionnaire scores were homogeneous across ethnicities. For Hypothesis 1, there are significant differences between White, Asian and BME students on perceived individuals' performance during TBL teamwork activities i.e., tRAT and tAPP- $(\mathrm{H}=6.814, \mathrm{df}=2, p$-value $=0.033)$. White and Asian students significantly score the highest perceived individual performance during such activities (mean ranks 75.60 and 75.48, respectively), with BME students scoring significantly lower $($ mean rank $=54.71)$. Therefore, Hypothesis 1 is rejected.

For Hypothesis 2, no significant differences between White, Asian and BME students on perceived individuals' adjustment and support during the aforementioned teamwork activities were found $(\mathrm{H}=4.974$, df $=2, p$-value $=0.083)$. Therefore, Hypothesis 2 is accepted.

For Hypothesis 3, there are significant differences between White, Asian and BME students on individuals' perceived decision-making during TBL teamwork activities $(\mathrm{H}=6.313, \mathrm{df}=2, p$-value $=0.043)$. Asian students significantly show the highest perceived participation in teams' decision-making processes during team activities (mean rank $=79.00$ ), followed by White students (mean rank $=73.50$ ) and BME students $($ mean rank $=55.81)$. Therefore, Hypothesis 3 is rejected.

\section{Discussion}

This empirical study investigates the effects of the TBL model in teamwork performance across ethnicities in a large, diverse engineering cohort. Specifically, it assesses how 
individual performance, individual adjustment and support, and decision-making abilities were perceived across White, Asian and BME. As such, this study does not seek to provide a casual model of the factors affecting the level of the reported perceived skills; instead, it pursues an exploration of the student perceptions with regards to their experiences with a TBL engineering module.

Drawing from the principles of the social constructivism learning theory (Figure 2) on which TBL is grounded (Vygotsky 1980), the educator acts as an expert guide to learning by guiding the discussion generated in the social context of a class organised in a number of diverse teams. Such guided discussion is originated from the outcomes of authentic application exercises and minimises more conventional passive learning strategies in the class. TBL also enables students to compare their understandings with those of their peers during the tRAT and the application exercises, and this induces an internal reflection process of dealing with conflicting understandings, opinions and evidence to build new schemas in line with the social constructivism learning theory. Also learners go through a reflection process on the received feedback on their own individual performance during TBL tasks.

\section{Insert Figure 2 here}

In relation to Hypothesis 1, significant differences in perceived individual performance across the three ethnicity categories were found; i.e., the implementation of TBL seems not to have been able to completely remove perceived differences in individuals' performance between White, Asian and BME engineering students during teamwork activities. Although, several measures have been recently launched by the UK 
government to drive change in tackling the attainment and achievement gap between ethnic groups across higher education institutions (DiversityUK 2019), there is still a significant lack of rigorous, theory-underpinned research to help understand the experiences of BME students in higher education that can recognise the potential grounds behind their prospective lower individual performance. Despite the solid theoretical grounds of the TBL model underpinned by the idea that learning and development are fundamentally tied to communicative interactions with others, individuals' performance are also related to inherent characteristics to the unique social and cultural context of the learners and their process of learning in a team. In this regard, Cotton et al. uncovered a series of individual experiences aligned with our finding (Cotton, Joyner et al. 2016). BME students were observed to be more likely extrinsically motivated to attend university (e.g., by future career, course reputation or family influences) compared to their White counterparts, who were more likely to be more intrinsically motivated (e.g., by interest in the subject or personal development). The researchers found out how the family influence might end up in BME students being more likely to apply for courses in which they have minor interest, therefore inducing a significant lack of engagement with the subject and adopting surface learning approaches. BME students have also reported to encounter external, environmental obstacles that inhibited their experience of fulfilling their psychological needs for competence, relatedness and autonomy; thus possibly undermining their desire to achieve their full learning potential in some cases (Bunce, King et al. 2019).

In relation to Hypothesis 2, significant differences in perceived adjustment and support across the three ethnicity categories were not found; i.e., the implementation of TBL seems to have been able to promote empathic attitudes to support weaker peer team members between White, Asian and BME engineering students during teamwork 
activities. This result is well in line with the recent findings that evidenced how TBL had facilitated the acquisition of interpersonal collaborative skills, including communicating with team members, managing personalities and working styles, and developing commitment to the team (Walker, Lang et al. 2020).

Unlike other research studies which identified ethnicity as a factor that had caused disempowerment in TBL environments in terms of peers' work adjustment (Cartwright 2015), the observations from our study on a TBL engineering module point out that students consistently adjusted their individual work style to support others regardless of their ethnic background, and for the benefit of the team success in solving the assigned tasks. While the connection between knowledge construction and the social learning environment characterised by the adjustment and support of team members is buoyed by the social-constructivist learning theory (Vygotsky 1980), most of the TBL literature has been focused on providing evidence for improved learning outcomes in different subjects (Haidet, Kubitz et al. 2014, Swanson, McCulley et al. 2019), particularly across STEM disciplines (Greetham and Ippolito 2018, Parappilly, Woodman et al. 2019, Leupen 2020). However, little has been done so far to develop rigorous research to ascertain the factors related to behavioural changes towards working in TBL teams or to the student perceptions of the model and the learning gained from applying it (Preast 2012, AlvarezBell, Wirtz et al. 2017, Cunha, Amendola et al. 2018).

In relation to Hypothesis 3, significant differences in perceived individual decision-making across the three ethnicity categories were found; i.e., the implementation of TBL seems not to have been able to equally promote perceived individuals' decisionmaking during teamwork activities. Despite the importance of the TBL educator role to provide a reflective guidance process as a way to promote an open and inclusive social learning environment, such guide may not be necessarily significant to improve team's 
quality of decision-making (Alizadeh, Mirzazadeh et al. 2017). Instead, individual's participation in decision-making processes within teams is largely affected by the power distance and individualism constructs characterising diverse teams (García-Cabrera and García-Soto 2010). Although usually applied in the context of working environments as a proxy of the extent to which the less powerful members accept and expect that power is distributed unequally (Hofstede 2011), working teams characterised by a low power distance show greater disposition towards participatory decision-making since hierarchy is understood by its members as inequality of roles, thus resulting in higher interaction between team members (Bochner and Hesketh 1994) and diluting the effect of working identities characterised by dominant-subservient interactions in ethnic-diverse teams (Gulati and Carbado 2000). In the particular case of TBL, several case studies have reported that BME students have blamed themselves for their subordination accepting their working identities across their teams based on a narrative of lacking self-confidence in their academic skills or valuing others' opinions over their owns (Hunn 2014, Cartwright 2017).

Individualism has also been associated with the lower individual willingness to participate in decision-making within their teams (Bochner and Hesketh 1994, Pheng and Yuquan 2002). Figure 3 illustrates that students' adjustment and support to peers strongly correlates with their participation in decision-making. Individualist attitudes of students reflected by a perceived poorer support to their peers (i.e., low Q2 scores) seem to be related to more individualistic approaches towards the process of decision-making when working in teams (i.e., low Q3 scores). Nevertheless, this effect is not only observed across the BME category, but also in the White and Asian groups, and therefore individualism may not seem to be a plausible explanation behind the lower perceived participation of BME students in decision-making. 


\section{Insert Figure 3 here}

Overall, the results reported in this work provide a knowledge base of how engineering students perceive their peers' performance in a TBL-based module rather than a systemic model to determine the causes of such perceptions. Although diverse teams bring a wide assortment of knowledge and perspectives that promotes more creative and innovative outcomes (Van Knippenberg and Schippers 2007), engineering educators and higher education institutions should be mindful of the fact that the implementation of TBL by itself does not necessarily remove the perceptions of poorer individual performance and decision-making skills of minority ethnics.

These results cannot certainly be interpreted to be exclusively subject-related, but more likely to be a combination of the students' cultural and social background, so making students aware of good practice on how to deal with conflicting opinions and decision making skills is likely to be needed if TBL is implemented across large, diverse cohorts. For instance, the development of a team contract at the beginning of the TBL module that includes expectations, individual and joint responsibilities and communications plans can be a potential tool to improve students' accountability and perceived levels of individual performance and decision making (Schwartz 1994). Also, supporting BME's general interest in the engineering subject can improve their perception of the educator as a learning facilitator, and ensuring their ability to thrive in a problem-based education setting such as TBL may increase their awareness of their own accountability (Jaeger and Adair 2014). 
Although our findings shade light into the social context of TBL across mixedethnicity teams and certainly show common trends with recent research on TBL, it is not without its limitations. Overall, generalisability may be limited to similar cohorts of finalyear engineering students whose teams have been purposefully formed to account for diversity factors, and this may represent a limited picture of the average cohort across a number of home and overseas institutions. Furthermore, our sample group had been previously introduced to personality style-based tests (i.e. Belbin's test) and conflict resolution workshops in their full-year engineering design modules, this potentially increasing students' awareness about good teamwork practice. Data were collected using a peer-assessment instrument which makes possible to have introduced some undesirable bias. However, peer-evaluation has proved to be more reliable than self-evaluations and evaluations only based on the educator views about the students' performance in their teams (Battur, Patil et al. 2016).

Rigorous methodological approaches to investigate the social context of TBL is still under development and the authors of this work have the confidence that it will serve as a call for building research capacity to shape the evolution of the model and thus, benefit higher education institutions from providing more global and inclusive student experience models to respond to the $21^{\text {st }}$ century demands from industries, governments and businesses. 


\section{References}

Alizadeh, M., A. Mirzazadeh, D. X. Parmelee, E. Peyton, L. Janani, G. Hassanzadeh and S. Nedjat (2017). "Uncover it, students would learn leadership from Team-Based Learning (TBL): The effect of guided reflection and feedback." Med Teach 39(4): 395-401.

Alvarez-Bell, R. M., D. Wirtz and H. Bian (2017). "Identifying keys to success in innovative teaching: Student engagement and instructional practices as predictors of student learning in a course using a team-based learning approach." Teaching \& Learning Inquiry 5(2): 128-146.

Au, K. H. (1998). "Social Constructivism and the School Literacy Learning of Students of Diverse Backgrounds." Journal of Literacy Research 30(2): 297-319.

Ballen, C. J., C. Wieman, S. Salehi, J. B. Searle and K. R. Zamudio (2017). "Enhancing Diversity in Undergraduate Science: Self-Efficacy Drives Performance Gains with Active Learning." CBE life sciences education 16(4): ar56.

Battur, S., M. S. Patil, P. Desai, M. Vijayalakshmi, M. M. Raikar, P. Hegde and G. H. Joshi (2016). Enhancing the Students Project with Team Based Learning Approach: A Case Study. 2016 IEEE 4th International Conference on MOOCs, Innovation and Technology in Education (MITE).

Baughman, J., L. Hassall and X. W. Xu (2019). "Comparison of student team dynamics between nonflipped and flipped versions of a large-enrollment sophomore design engineering course." Journal of Engineering Education 108(1): 103-118.

Beichner, R. J., J. M. Saul, D. S. Abbott, J. J. Morse, D. Deardorff, R. J. Allain, S. W. Bonham, M. H. Dancy and J. S. Risley (2007). "The student-centered activities for large enrollment undergraduate programs (SCALE-UP) project." Research-based reform of university physics 1(1): 2-39.

Betta, M. (2016). "Self and others in team-based learning: Acquiring teamwork skills for business." Journal of Education for Business 91(2): 69-74.

Bochner, S. and B. Hesketh (1994). "Power distance, individualism/collectivism, and job-related attitudes in a culturally diverse work group." Journal of cross-cultural psychology 25(2): 233257.

Brutus, S. and M. B. Donia (2010). "Improving the effectiveness of students in groups with a centralized peer evaluation system." Academy of Management Learning \& Education 9(4): 652662.

Bryman, A. (2016). Social research methods, Oxford university press.

Bunce, L., N. King, S. Saran and N. Talib (2019). "Experiences of black and minority ethnic (BME) students in higher education: applying self-determination theory to understand the BME attainment gap." Studies in Higher Education: 1-14.

Cartwright, N. (2015). Pedagogy \& inequality: a case-study of team-based learning \& race. 8th Equality, Diversity and Inclusion International Conference (EDI 2015).

Cartwright, N. (2017). Identity and (dis) empowerment in team-based learning. Conference Proceedings. The Future of Education, libreriauniversitaria. it Edizioni.

Chao, I. T. and M. C. Pardy (2014). "Your Way or My Way? Integrating Cultural Diversity into Team-based Learning at Royal Roads University." Engaging Students in Life-Changing Learning: 215.

Cotton, D. R. E., M. Joyner, R. George and P. A. Cotton (2016). "Understanding the gender and ethnicity attainment gap in UK higher education." Innovations in Education and Teaching International 53(5): 475-486.

Cramer, D. (2003). Fundamental statistics for social research: Step-by-step calculations and computer techniques using SPSS for Windows.

Cunha, M. L. D., F. Amendola, M. M. F. Samperiz and A. G. D. Mohallem (2018). "Evaluation of student perception of the Team-based Learning method (APA-TBL): Instrument construction and validation." Nurse Education in Practice 33: 141-147.

de Los Rios, I., A. Cazorla, J. M. Díaz-Puente and J. L. Yagüe (2010). "Project-based learning in engineering higher education: two decades of teaching competences in real environments." Procedia-Social and Behavioral Sciences 2(2): 1368-1378. 
DiversityUK. (2019). "Universities must do more to tackle ethnic disparity." from https://diversityuk.org/universities-must-do-more-to-tackle-ethnic-disparity/.

Dori, Y. J., J. Belcher, M. Bessette, M. Danziger, A. McKinney and E. Hult (2003). "Technology for active learning." Materials Today 6(12): 44-49.

Freeman, M. (1995). "Peer Assessment by Groups of Group Work." Assessment \& Evaluation in Higher Education 20(3): 289-300.

Freeman, S., S. L. Eddy, M. McDonough, M. K. Smith, N. Okoroafor, H. Jordt and M. P. Wenderoth (2014). "Active learning increases student performance in science, engineering, and mathematics." Proceedings of the National Academy of Sciences 111(23): 8410-8415.

Gallegos, P. J. and J. M. Peeters (2011). "A measure of teamwork perceptions for team-based learning." Currents in Pharmacy Teaching and Learning 3(1): 30-35.

García-Cabrera, A. M. and M. G. García-Soto (2010). "The impact of cultural resources on multicultural team performance." Innovar 20(38): 141-160.

Greetham, M. and K. Ippolito (2018). "Instilling collaborative and reflective practice in engineers: using a team-based learning strategy to prepare students for working in project teams." Higher Education Pedagogies 3(1): 510-521.

Gulati, M. and D. W. Carbado (2000). "Working Identity." Faculty Scholarship: 1302.

Haak, D. C., J. HilleRisLambers, E. Pitre and S. Freeman (2011). "Increased structure and active learning reduce the achievement gap in introductory biology." Science 332(6034): 1213-1216.

Haidet, P., K. Kubitz and W. T. McCormack (2014). "Analysis of the Team-Based Learning Literature: TBL Comes of Age." Journal on excellence in college teaching 25(3-4): 303-333.

Hartikainen, S., H. Rintala, L. Pylvas and P. Nokelainen (2019). "The Concept of Active Learning and the Measurement of Learning Outcomes: A Review of Research in Engineering Higher Education." Education Sciences 9(4): 19.

Hernández-de-Menéndez, M., A. Vallejo Guevara, J. C. Tudón Martínez, D. Hernández Alcántara and R. Morales-Menendez (2019). "Active learning in engineering education. A review of fundamentals, best practices and experiences." International Journal on Interactive Design and Manufacturing 13(3): 909-922.

Hofstede, G. (2011). "Dimensionalizing cultures: The Hofstede model in context." Online readings in psychology and culture 2(1): 2307-0919.1014.

Hrynchak, P. and H. Batty (2012). "The educational theory basis of team-based learning." Medical teacher 34(10): 796-801.

Hsieh, C. and L. Knight (2008). "Problem-Based Learning for Engineering Students: An Evidence-Based Comparative Study." The Journal of Academic Librarianship 34(1): 25-30.

Hunn, V. (2014). "African American students, retention, and team-based learning: A review of the literature and recommendations for retention at predominately white institutions." Journal of Black Studies 45(4): 301-314.

Jaeger, M. and D. Adair (2014). "The influence of students' interest, ability and personal situation on students' perception of a problem-based learning environment." European Journal of Engineering Education 39(1): 84-96.

Jeno, L. M., A. Raaheim, S. M. Kristensen, K. D. Kristensen, T. N. Hole, M. J. Haugland and S. Mæland (2017). "The Relative Effect of Team-Based Learning on Motivation and Learning: A Self-Determination Theory Perspective." CBE life sciences education 16(4): ar59.

Lane, D. R. (2008). "Teaching skills for facilitating team-based learning." New Directions for Teaching and Learning 2008(116): 55-68.

Lehmann, M., P. Christensen, X. Du and M. Thrane (2008). "Problem-oriented and project-based learning (POPBL) as an innovative learning strategy for sustainable development in engineering education." European Journal of Engineering Education 33(3): 283-295.

Leon, A. C. (1998). 3.12 - Descriptive and Inferential Statistics. Comprehensive Clinical Psychology. A. S. Bellack and M. Hersen. Oxford, Pergamon: 243-285.

Leupen, S. (2020). Team-Based Learning in STEM and the Health Sciences. Active Learning in College Science: The Case for Evidence-Based Practice. J. J. Mintzes and E. M. Walter. Cham, Springer International Publishing: 219-232.

Mann, L., R. Chang, S. Chandrasekaran, A. Coddington, S. Daniel, E. Cook, E. Crossin, B. Cosson, J. Turner, A. Mazzurco, J. Dohaney, T. O'Hanlon, J. Pickering, S. Walker, F. Maclean 
and T. D. Smith (2020). "From problem-based learning to practice-based education: a framework for shaping future engineers." European Journal of Engineering Education: 1-21.

Michaelsen, L. K., M. Sweet and D. X. Parmelee (2008). Team-based learning : small group learning's next big step. San Francisco, CA, Jossey-Bass.

Miller, D. L. (2003). "The stages of group development: A retrospective study of dynamic team processes." Canadian Journal of Administrative Sciences/Revue Canadienne des Sciences de l'Administration 20(2): 121-134.

Mitchell, J., A. Nyamapfene, K. Roach and E. Tilley (2019). "Philosophies and pedagogies that shape an integrated engineering programme." Higher Education Pedagogies 4(1): 180-196.

Najdanovic-Visak, V. (2017). "Team-based learning for first year engineering students." Education for Chemical Engineers 18: 26-34.

O'Neill, T. A. and E. Salas (2018). "Creating high performance teamwork in organizations." Human Resource Management Review 28(4): 325-331.

O’Neill, T., N. Larson, J. Smith, M. Donia, C. Deng, W. Rosehart and R. Brennan (2019). "Introducing a scalable peer feedback system for learning teams." Assessment \& Evaluation in Higher Education 44(6): 848-862.

Palego, C. and I. Pierce (2020). "Inspiring a self-reliant learning culture while brewing the next silicon valley in north Wales." Education Sciences 10(3).

Parappilly, M., R. J. Woodman and S. Randhawa (2019). "Feasibility and Effectiveness of Different Models of Team-Based Learning Approaches in STEMM-Based Disciplines." Research in Science Education.

Park, H.-R., C.-J. Kim, J.-W. Park and E. Park (2015). "Effects of team-based learning on perceived teamwork and academic performance in a health assessment subject." Collegian 22(3): 299-305.

Pheng, L. S. and S. Yuquan (2002). "An exploratory study of Hofstede's cross-cultural dimensions in construction projects." Management Decision.

Planas-Lladó, A., L. Feliu, G. Arbat, J. Pujol, J. J. Suñol, F. Castro and C. Martí (2020). "An analysis of teamwork based on self and peer evaluation in higher education." Assessment \& Evaluation in Higher Education: 1-17.

Ployhart, R. E., A. J. Nyberg, G. Reilly and M. A. Maltarich (2014). "Human capital is dead; long live human capital resources!" Journal of management 40(2): 371-398.

Preast, V. (2012). "The development of team trust over time and its effect on performance when using Michaelsen's Team-Based Learning."

Prince, M. (2004). "Does active learning work? A review of the research." Journal of Engineering Education 93(3): 223-231.

Schwartz, S. H. (1994). "Beyond individualism/collectivism: New cultural dimensions of values." Shekhar, P. and M. Borrego (2018). "'Not hard to sway': a case study of student engagement in two large engineering classes." European Journal of Engineering Education 43(4): 585-596.

Shinde, V. and A. Kolmos (2011). Students Experiences in Aalborg PBL Model: A Case Study. SEFI Annual Conference, Lisbon.

Stevenson, K., C. Seenan, G. Morlan and W. Smith (2012). "Preparing students to work effectively in interprofessional health and social care teams." Quality in Primary Care 20(3): 227230.

Swanson, E., L. V. McCulley, D. J. Osman, N. Scammacca Lewis and M. Solis (2019). "The effect of team-based learning on content knowledge: A meta-analysis." Active learning in higher education 20(1): 39-50.

Theobald, E. J., M. J. Hill, E. Tran, S. Agrawal, E. N. Arroyo, S. Behling, N. Chambwe, D. L. Cintrón, J. D. Cooper, G. Dunster, J. A. Grummer, K. Hennessey, J. Hsiao, N. Iranon, L. Jones, H. Jordt, M. Keller, M. E. Lacey, C. E. Littlefield, A. Lowe, S. Newman, V. Okolo, S. Olroyd, B. R. Peecook, S. B. Pickett, D. L. Slager, I. W. Caviedes-Solis, K. E. Stanchak, V. Sundaravardan, C. Valdebenito, C. R. Williams, K. Zinsli and S. Freeman (2020). "Active learning narrows achievement gaps for underrepresented students in undergraduate science, technology, engineering, and math." Proceedings of the National Academy of Sciences 117(12): 6476-6483. 
Van Knippenberg, D. and M. C. Schippers (2007). "Work group diversity." Annu. Rev. Psychol. 58: $515-541$.

Vygotsky, L. S. (1980). Mind in society: The development of higher psychological processes, Harvard university press.

Walker, E. R., D. L. Lang, B. A. Caruso and L. Salas-Hernandez (2020). "Role of team dynamics in the learning process: a mixed-methods evaluation of a modified team-based learning approach in a behavioral research methods course." Advances in Health Sciences Education 25(2): 383399.

Whitley, H. P., E. Bell, M. Eng, D. G. Fuentes, K. L. Helms, E. D. Maki and D. Vyas (2015). "Practical Team-Based Learning from Planning to Implementation." American journal of pharmaceutical education 79(10): 149-149. 
Tables with captions

Table 1 Descriptive statistics based on normalised $X_{i}$ values

\begin{tabular}{|c|c|c|c|c|c|c|c|c|c|c|c|c|}
\hline Question & \multicolumn{3}{|c|}{ Mean } & \multicolumn{3}{|c|}{ Standard Deviation } & \multicolumn{3}{|c|}{ Minimum } & \multicolumn{3}{|c|}{ Maximum } \\
\hline Ethnicity & Asian & BME & White & Asian & BME & White & Asian & BME & White & Asian & BME & White \\
\hline $\begin{array}{l}\text { Q1: } \\
\text { Performance }\end{array}$ & 1.03 & 0.94 & 1.02 & 0.10 & 0.18 & 0.11 & 0.84 & 0.25 & 0.72 & 1.26 & 1.19 & 1.28 \\
\hline $\begin{array}{l}\text { Q2: } \\
\text { Adjustment }\end{array}$ & 1.03 & 0.93 & 1.02 & 0.12 & 0.21 & 0.12 & 0.77 & 0.25 & 0.63 & 1.25 & 1.20 & 1.28 \\
\hline and support & & & & & & & & & & & & \\
\hline Q3: & & & & & & & & & & & & \\
\hline $\begin{array}{l}\text { Decision- } \\
\text { making }\end{array}$ & 1.03 & 0.94 & 1.02 & 0.11 & 0.19 & 0.11 & 0.78 & 0.25 & 0.64 & 1.28 & 1.19 & 1.30 \\
\hline
\end{tabular}


Figure 1
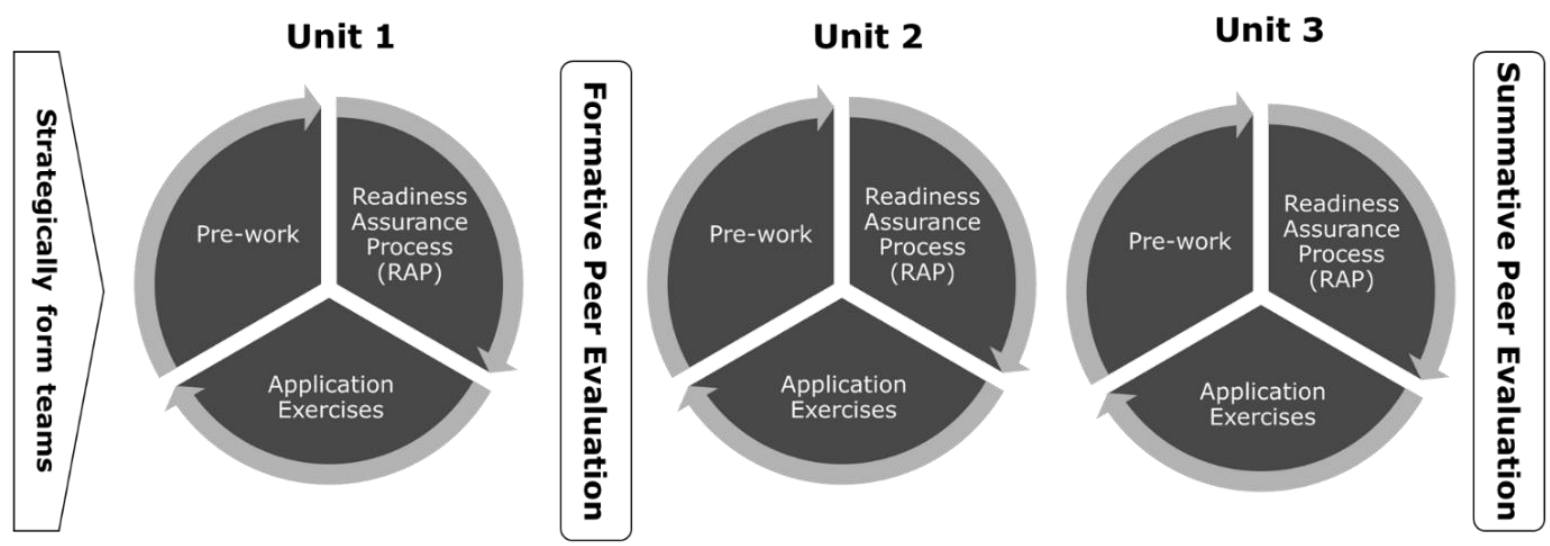
Figure 2

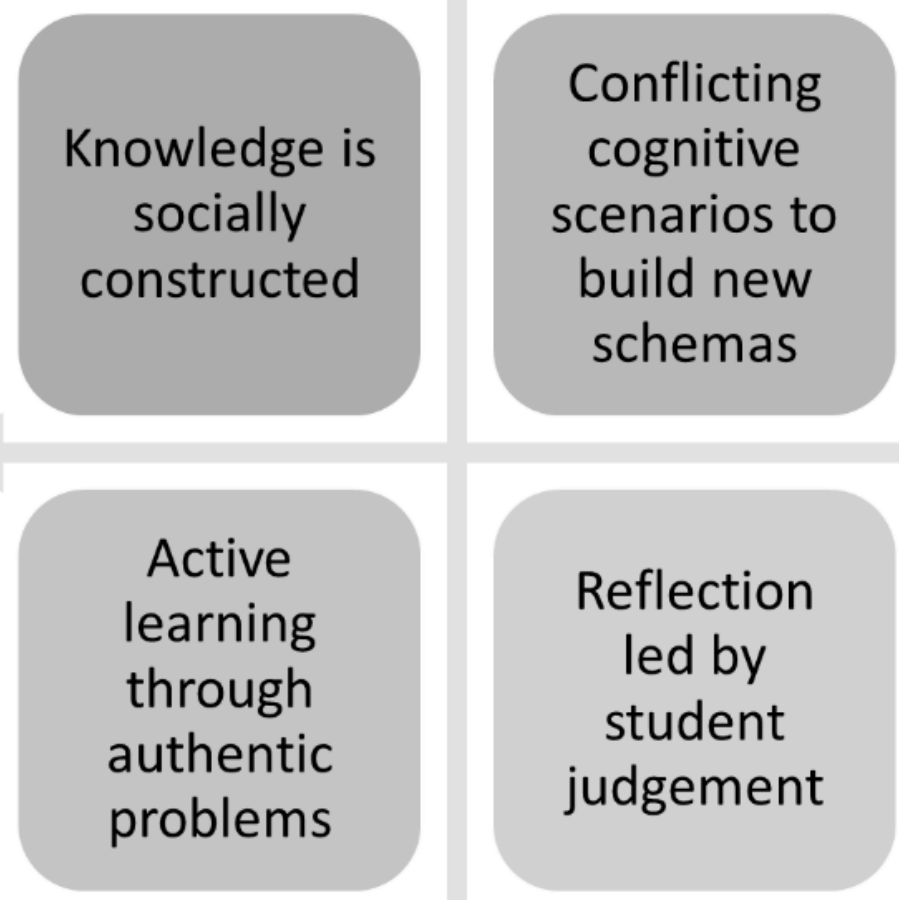


Figure 3

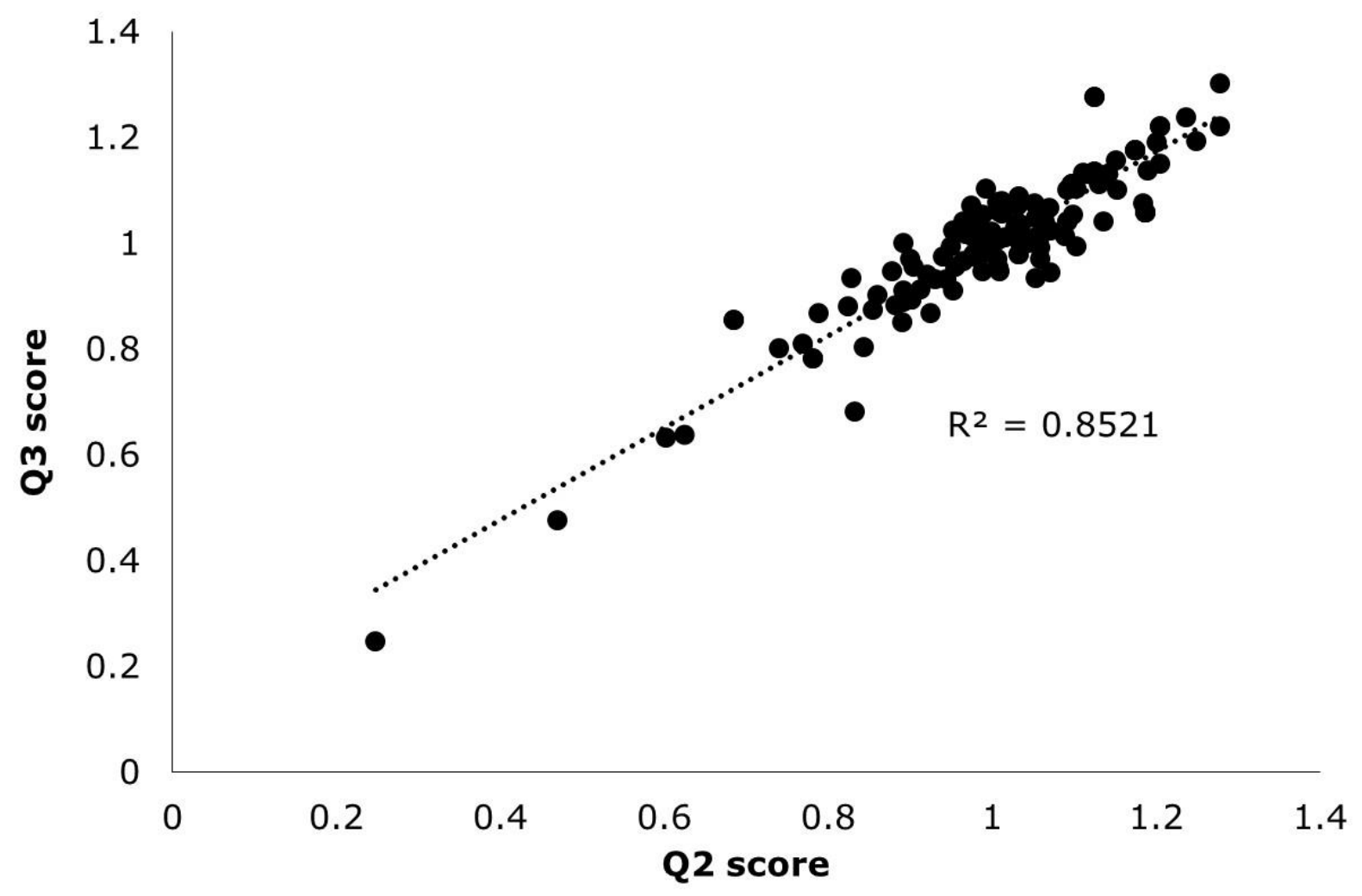




\section{Figure Captions}

Figure 1 Exemplar of a TBL sequence for a module consisting of three different units

Figure 2 Elements of the social constructivist learning (Vygotsky 1980)

Figure 3 Correlation between Q2 scores (individual adjustment and support) and Q3 scores (decision-making) for the sample group 